\title{
Guest editorial: Resilience and Ethics in Social Systems
}

This special issue follows from the 2017 conference of the American Society for Cybernetics (ASC), which took place in the week of the 7-12 August in Salem Massachusetts. The conference theme was "Resilience and Ethics: Implications", and its goal was:

...to increase the resilience of resilience by considering the many ways in which the concept is - or might be - understood. Psychology, business, systems, media, material science, and philosophy, among others, consider resilience a key concept, though each defines resilience somewhat differently and applies resilience in a different context.[1]

The use of the term 'resilience' goes back to the early nineteenth century, referring to "the capability of a strained body to recover its size and shape after deformation" (Merriam Webster, 2018). This term from engineering and the physical sciences was extended by ecologists to refer to the dynamic adaptability of biological systems. An early and well known example is Crawford Holling's paper 'Resilience and Stability of Ecological Systems':

Resilience determines the persistence of relationships within a system and is a measure of the ability of these systems to absorb changes of state variables, driving variables, and paramaters [sic], and still persist. In this definition resilience is the property of the system and persistence or probability of extinction is the result. (Holling, 1973)

The concept of resilience has also been adopted in psychology to refer to a quality present in an individual. For example, it has frequently been used in child developmental studies to describe a child's capacity to overcome adverse events (Masten \& Coatsworth, 1998), including the ability to overcome extreme challenges such as famine, war, or serious physical or psychological trauma (Day et al., 2011). By extension from the individual to the group, organisations are also described as possessing the property of resilience if they can overcome unforeseen events in their environment. A clear example of this extension is a report on 'Organisational Accidents and Resilient Organisations' for the Research Council of Norway [2]. The report explicitly adopted the Merriam Webster definition of resilience as a physical property, and then applied it to organisational resilience in referring to the properties of "an organisation that has a capacity to accommodate failures and disturbances without producing serious accidents" (Morud et al., 2004).

The term 'resilience', therefore, involves the metaphorical application of a concept from physics and engineering (the capacity for recovery of a physical material from deformation) to three quite different domains: (i) the ability of a biological population to adapt to a changing environment, (ii) individual psychology, and (iii) social organisations.

Metaphors can provide creative insight, and the extension of the concept of resilience may well have been productive in moving forward our understanding. It has certainly been productive in creating a discourse-and generating academic activity. At the same time, the application of the concept in such different domains can create confusion about the mechanisms involved. It is hard, therefore, to disagree with Christopher Day et al. (2011) who describe 'resilience' as a multi-faceted and unstable construct. In particular, the shift of the concept from an ecological to a social context can be problematic. Whereas the ability to sustain itself is a precious quality of any ecological system, the same cannot always be said in terms of social relations (MacKinnon and Derickson, 2013; Derickson, 2016). 
Within the multi-faceted domain of resilience, a distinction can be proposed. Some explanations of resilience identify a quality in a system whose presence itself explains the system's survival. This is the case, for example, in studies that identify a psychological trait of resilience (or the related quality of 'grit') and which assess its presence or absence in individuals. Other researchers, however, conceive of resilience as a dynamic aspect resting on the interaction between the attributes of an individual and the environmental and social factors that are intermingled in a person's life (Luthar \& Brown, 2007; Day et al., 2011; Mansfield, Beltman \& Price, 2014). From the latter perspective, resilience is a relational phenomenon, and is at least partially determined by the behaviour of individuals, and by the behaviour of those who determine the characteristics of the environment in which those individuals live. As Pille Bunnell (2019) puts it in her contribution to this issue, resilience can be understood "as a way of being in the world; a manner of attempting to articulate the complexities of our relationships in a systemic coexistence with each other and our earth". If we understand resilience in this way, in terms of our relationships with each other and with the environment, then it is a concept intimately linked with ethical considerations.

What then, can cybernetics offer to move forward research into resilience? Firstly, cybernetics has a long history of making sense of the similarities and distinctions in multiple discourses. The ideas of generations of cybernetic thinkers can be brought to bear in clarifying the isomorphisms and metaphorical relationships between the domains of the physical, ecological, psychological, and social. For example, Gregory Bateson critiqued the metaphorical use of the concept of 'power', derived from physics, in the domains of the social and the biological (see Bateson (1974) and Guddemi (2010)). It may be useful today to consider how Bateson would have viewed a similar metaphorical application of physical properties in the literature of resilience.

Secondly, one of the principal concerns of cybernetics has been to explain the on-going survival of systems and their adaptation to the environment. To take only two of the most evident examples, the formulation of autopoiesis by Humberto Maturana and Francisco Varela (Maturana and Varela, 1980) concerns precisely the self-reproduction of systems in a changing environment, while Stafford Beer's analysis of viability in the field of management cybernetics (e.g. Beer, 1972) has much in common with Holling's description of resilience (cited above). These and other cybernetic perspectives provide theoretical models that can be used to explain the structures and processes which enable entities to survive and thrive, or lead them to disappear. Two papers addressing this topic are: Robert Cutler and Alexander von Lingen (2019); and Philip Baron and Anne Baron (2019). The former relates to the practical design of resilient organisations with empirical reference to the European empirical Parliament's development of institutional capacities, while the latter paper proposes a set of common attributes that describe ethically resilient educators in both the tertiary and the pre primary level.

Cybernetics also offers a valuable point of reference in light of criticisms of resilience such as those of Kate Driscoll Derickson (2016, p. 161), for whom resilience "fetishizes the status quo and is not suited to the emancipatory social change desired by groups that have employed the term". Talk of increasing resilience has been critiqued as regressive in that maintaining existing economic and social relationships sustains the inequalities and injustices that these relationships produce. This aspect of resilience is addressed in a contribution to this special issue by Dai Griffiths (2019), who argues that the methods of governance inspired by neoliberalism can lead to the unconsidered maximization of transparency and accountability. This, he proposes, can suppress the unacknowledged and unrecognised conversations and 
processes that contribute to the resilience of both the organisation and its members. To understand resilience in this socio-economic context we must therefore always ask resilience to what, of whom, to whose benefit and by what process.

Geoff DeVerteuil and Oleg Golubchikov (2016) have suggested a critical reframing of resilience as a "metaphor for change, not against change", understanding it as a necessary underpinning for future transformations. This approach may find support in the combination of stability and change that is a feature of cybernetic processes. Consider, for instance, the eponymous cybernetic example of steering a ship. We can understand the cybernetic system of steering in terms of resilience, as the maintenance of a steady course despite changes in the environment. This ability to maintain a trajectory is essential not just to reaching the destination to which one is heading but also to the ability to change direction, for instance to explore new areas of coastline that were not known at the outset of the journey. This combination of stability and the generation of new possibilities (interpretations and observations) is a quality of cybernetic actions. These include conversation, learning, reflection, and designing in diverse contexts, as explored in contributions to this issue from Philip Baron and Christiane Herr (2019), and Megan Ryland and Tom Scholte (2019). Herr and Baron present a comparative analysis of their cybernetically informed pedagogy that emphasises ethical settings for learning on the basis of equality and social inclusion in the classroom context. They highlight the role of adaptation as an important feature in their respective approaches that are adapted to their distinctly different contexts - China and South Africa. Ryland and Scholte use a blended methodology (grounded theory and action research) to study forum theatre as a means to increase context awareness in the workplace where participants are experiencing conflict.

Of course, one can also speak of the resilience of the field of cybernetics itself. In his time as ASC President, Ranulph Glanville (2011) stressed the need for cybernetics to be practiced in the light of its own insights. In this, he echoed Margaret Mead's (1968) address to the inaugural conference of the ASC, where she challenged the society to apply the ideas of cybernetics to itself. This observation led to the development of second-order cybernetics, which Glanville (2009) suggested should have "the role of the conscience of cybernetics" in order to maintain the coherence of the field:

...it's where we look at the concepts and assumptions that cybernetics runs on, or which it tries to explain, and where we attempt to deal with them in a manner that reflects our understandings - i.e., cybernetically. That's how the cybernetics of cybernetics actually is the cybernetics of cybernetics! So I believe there is an area (perhaps only tiny) where we care for what is at the heart of cybernetics, making sure it's healthy and growing well. (Glanville, 2009, p. 198)

In this light, this special issue includes papers concerned with core second-order cybernetic themes of recursion and the inclusion of the observer. Lance Nizami (2019a, 2019b) presents a critique of infant pyschophysics, using the perspective of second-order cybernetics to show that experiments to determine hearing thresholds in infants actually infer an ability of the laboratory as a whole. Faisal Kadri (2019) connects Glanville's (2001) discussion of as_if and as_is to theories of measurement, and in so doing builds a valuable bridge between secondorder cybernetics and scientific practice. Thomas Fischer's (2019) paper presents a critical review of Glanville's arguments regarding transcomputability and the value of being out of control, distinguishing between strict control and the testing of exhaustive permutations. Ben Sweeting (2019) extends second-order cybernetic reflections on ethics and design, putting 
forward a way in which ethics may be applied recursively to itself, in the sense that ethical discourse is an activity to which ethical considerations and questions apply.

As can be seen from the brief descriptions of the papers above, this special issue is informed by a wide range of cybernetic models and explanations. Both the ASC and cybernetics more generally are characterised by the diversity of participants' disciplines and backgrounds. This heterogeneity creates a challenge to the idea of strict academic disciplines. Transdisciplinary and meta-disciplinary approaches are commonplace in the conversations, presentations, and academic publications, with antidisciplinary ideas valued. It is our hope, as editors, that the contributions will enrich current perspectives on resilience in individuals and social systems, and that cybernetics continues to make significant interventions in this field.

\section{Publication process}

The ASC is pleased to continue its relationship with Kybernetes, which has previously published special issues developed from ASC conferences in Troy, NY (Glanville and Sweeting, 2011), Asilomar, CA (Glanville and Griffiths, 2013), Bolton, UK (Glanville et al., 2014), Washington, DC (Baron et al., 2015), and Olympia, WA (Baron et al., 2017).

In keeping with the publication tradition of the ASC, a paper publication track was available to those who submitted abstracts prior to the conference. The abstracts were reviewed by the conference organising committee. The authors of the accepted abstracts were then invited to present their work at the conference. Authors were invited to submit their final paper drafts through the ScholarOne portal after a two month interval, allowing time for them to revise and develop their work in light of discussions and debate at the conference. At this stage, the call was also opened to ASC members who had not attended the conference, who were invited to submit work in response to the theme. Each paper was then subjected to a rigorous doubleblind peer review including the guest editors' reconciliation. The reconciliation, which is also a feature in the ASC publication approach, is meant to assist the author in tying together any divergent peer reviews. Authors were requested to acknowledge reviewers' comments, which are checked by the guest editors for the adequacy of response to review critiques, keeping in mind that reviewers may also need to be challenged. This approach to publication was born out of the legacy of Ranulph Glanville and his supportive approach to scholarly publications. In this light, the method that the editorial team follow should also reflect a cybernetic approach: cybernetics is not just a way of thinking, it is also a way of doing.

\section{Acknowledgements}

We wish to thank the staff at Salem Waterfront Hotel \& Suites for hosting the conference as well as the panel of ASC members who organised the conference. The editors would like to thank the staff at Emerald, who publish Kybernetes; and the editors of Kybernetes lead by Prof. Gandolfo Dominici. Our guest editorial team would like to acknowledge the voluntary effort made by dedicated reviewers who took part in the publication of this issue making up the proceedings for the ASC2017 conference.

Philip Baron, Department of Electric and Electronic Engineering Technology, University of Johannesburg, Johannesburg, South Africa 
Delfina Fantini van Ditmar, Design Products Programme, Royal College of Art. London, $U K$

Dai Griffiths, The School of Education and Psychology, The University of Bolton, Bolton, $U K$

Ben Sweeting, School of Architecture and Design, University of Brighton, Brighton, UK

\section{Reference list}

Baron, P. \& Baron, A. (2019) "Ethically resilient teachers, what might that be?: A comparison across two educational levels: pre-school and university in South Africa", Kybernetes, Vol. 48 No. 4, pp.696-714, doi:10.1108/K-01-2018-0033

Baron, P. \& Herr, C. (2019) "Cybernetically informed pedagogy in two tertiary educational contexts: China and South Africa", Kybernetes, Vol. 48 No. 4, pp.727-739, doi:10.1108/K-122017-0479

Baron, P., Glanville, R., Griffiths, D., and Sweeting, B. (Eds.). (2015). Living in Cybernetics: Papers from the 50th Anniversary Conference of the American Society for Cybernetics. Special double issue of Kybernetes, Vol 44 No. 8/9. doi:10.1108/K-09-2015-0222.

Baron, P., Griffiths, D., and Sweeting, B. (Eds.). (2017). Action and Reflection: The Individual and the Collective. Special Issue of Kybernetes, Vol 46 No. 9.

Bateson, G. (1974). DRAFT: Scattered Thoughts for a Conference on "Broken Power." CoEvolution Quarterly, (Winter Solstice), pp 26-27.

Bunnell, P. (2019) "The soul of resilience", Kybernetes, Vol. 48 No. 4, pp.672-684, doi:10.1108/K-01-2018-0027

Cutler. R, von Lingen, A (2019) "An evolutionary phenomenology of resilience", Kybernetes, Vol. 48 No. 4, pp.685-695, doi:10.1108/K-11-2017-0460

Day, C., Edwards, A., Griffiths, A., and Gu, Q. (2011). Beyond survival: Teachers and resilience. In Key messages from ESRC-funded Seminar series Google Scholar. Nottingham: University of Nottingham, available at https://www.nottingham.ac.uk/research/groups/crelm/documents/teachers-resilience/teachersresilience.pdf (accessed 02 October 2018).

Derickson, K. D. (2016). Resilience is not enough. City, Vol. 20 No. 1, pp 161-166, doi: $10.1080 / 13604813.2015 .1125713$

DeVerteuil, G. and Golubchikov, O. (2016), "Can resilience be redeemed?", City, Vol. 20 No. 1, pp. 143-51. doi: 10.1080/13604813.2015.1125714 
Fischer, T. (2019) "Transcomputability, (Glanville's corollary of) Ashby's law of requisite variety and epistemic processes", Kybernetes, Vol. 48 No. 4, pp.793-804, doi:10.1108/K-112017-0457

Glanville, R. (2001), "An Observing Science", Foundations of Science, Vol. 6 No. 1, pp. $45-$ 75, doi: 10.1023/a:1011353225749

Glanville, R. (2009), "A (cybernetic) musing: the state of cybernetics", in The Black Boox, volume III: 39 steps, Edition Echoraum, Vienna, pp. 197-206. (Reprinted from: Cybernetics \& Human Knowing, Vol. 7 No. 2-3, pp. 151-59, 2000).

Glanville, R. (2011), "Introduction: A conference doing the cybernetics of cybernetics", Kybernetes, Vol. 40 No. 7/8, pp. 952-63. doi: 10.1108/03684921111160197

Glanville, R., and Griffiths, D. (Eds.). (2013). An ecology of ideas. Special double issue of Kybernetes, Vol. 42 No. 9/10.

Glanville, R., Griffiths, D., \& Baron, P. (Eds.). (2014). A circularity in learning. Special double issue of Kybernetes, Vol. 43 No. 9/10.

Glanville, R. and Sweeting, B. eds. (2011), Cybernetics: Art, design, mathematics-A metadisciplinary conversation: Papers from the 2010 conference of the American Society for Cybernetics, Special double issue of Kybernetes, Vol. 40 No. 7/8.

Griffiths, D. (2019) "Resilience and transparency in social systems", Kybernetes, Vol. 48 Issue: 4, pp.715-726, doi:10.1108/K-01-2018-0032

Guddemi, P. (2010). A multi-party dialogue about power and cybernetics. Integral Review, Vol. 6 No. 1, pp 187-207.

Holling, C.S. (1973), "Resilience and Stability of Ecological Systems", Annual Review of Ecology and Systematics, Vol. 4 No. 1, pp. 1-23, doi:10.1146/annurev.es.04.110173.000245

Kadri, F. (2019) "Are all observations measurements?", Kybernetes, Vol. 48 Issue: 4, pp.782792, doi:10.1108/K-11-2017-0450

Luthar, S. S., and Brown, P. J. (2007). Maximizing resilience through diverse levels of inquiry: Prevailing paradigms, possibilities, and priorities for the future. Development and psychopathology, Vol. 19 No. 3, pp 931-955.

MacKinnon, D., and Derickson, K. D. (2013). From Resilience to Resourcefulness: A Critique of Resilience Policy and Activism. Progress in Human Geography. Vol. 37 No. 2, pp 253-270. doi:10.1177/0309132512454775

Mansfield, C., Beltman, S., and Price, A. (2014). 'I'm coming back again!' The resilience process of early career teachers. Teachers and Teaching, Vol. 20 No. 5, pp 547-567.

Masten, A. S., and Coatsworth, J. D. (1998). The development of competence in favorable and unfavorable environments: Lessons from research on successful children. American psychologist, Vol. 53 No. 2, pp 205-220. 
Maturana, H. R., and Varela, F. J. (1980). Autopoiesis and cognition: The realization of the living. Reidel, Dodrecht, NL.

Mead, M. (1968), "The cybernetics of cybernetics", in von Foerster, H., White, J. D., Peterson, L. J. and Russell, J. K. (Eds.), Purposive Systems, Spartan Books, New York, NY, pp. 1-11.

Merriam Webster (2018). Definition of 'resilience', available at: https://www.merriamwebster.com/dictionary/resilience (accessed 26 September 2018).

Morud, J., Skjetne, P., Engeskaug, R., Bakke, M., Korhonen, E., and Lysberg, M. (2004). Organisational Accidents and Resilient Organisations: Five Perspectives (report to the Research Council of Norway). SINTEF, Trondheim, Norway.

Nizami, L. (2019a) "Too resilient for anyone's good: "Infant psychophysics" viewed through second-order cybernetics, part 1 (background and problems)", Kybernetes, Vol. 48 No. 4, pp.751-768, https://doi.org/10.1108/K-11-2017-0451

Nizami, L. (2019b) "Too resilient for anyone's good: "Infant psychophysics" viewed through second-order cybernetics, part 2 (re-interpretation)", Kybernetes, Vol. 48 No. 4, pp.769-781, doi:10.1108/K-05-2018-0238

Ryland, M. and Scholte, T. (2019). "Rehearsing resilience(and beyond): Facilitating secondorder observation of conflict in the university workplace through forum theatre", Kybernetes, Vol. 48 No. 4, pp.740-750, doi: 10.1108/K-11-2017-0459

Sweeting. B. (2019) "Applying ethics to itself: recursive ethical questioning in architecture and second-order cybernetics", Kybernetes, Vol. 48 No. 4, pp.805-815, doi: 10.1108/K-12-20170471

\section{[1] http://asc-cybernetics.org/asc2017/}

[2] 'Organisational Accident' here refers to rare but serious malfunctions involving both technology and many people operating at different organisational levels. Examples include nuclear power plant meltdowns, aviation disasters, and banking crashes. 